\title{
Regional Food Causing Symptoms of Gastroesophageal Reflux Disease
}

\author{
Jung Ho Park \\ Department of Internal Medicine, Kangbuk Samsung Hospital, Sungkyunkwan University College of Medicine, Seoul, Korea
}

Article: Foods inducing typical gastroesophageal reflux disease symptoms in Korea

Choe JW, Joo MK, Kim HJ, et al

(J Neurogastroenterol Motil 2017;23:363-369)

Food is an important contributor to functional gastrointestinal disorders (FGID). Food is associated with symptom onset or exacerbation in a significant proportion of FGID, ${ }^{1}$ and a low fermentable oligosaccharides, disaccharides, monosaccharides, and polyols (FODMAPs) diet have been associated with significant symptom improvement in patients with irritable bowel disease. ${ }^{2}$

However, there are several difficulties in revealing the correlation between food and symptoms of FGID. First, the types of foods consumed is very different depending on race, geographic specificity, diet habit, and culture. Second, there are many other symptominducing factors besides food, so it is difficult to see the relationship between symptoms and food alone. ${ }^{3}$ Lastly, the external condition of the patient will also be important, since psychological stress is widely believed to play a major role in FGID. ${ }^{4}$

In this issue of Journal of Neurogastroenterology and Motility, Choe et $\mathrm{al}^{5}$ tried to investigate the relationship between gastroesophageal reflux disease (GERD) and regional food, and concluded that hot spicy stews, rice cakes, ramen noodles, fried foods, and topokki were the foods frequently inducing typical symptoms in Korea. These results are consistent with those of previous reports in Western countries that high-fat foods, spicy foods, chocolate, mint, and citrus fruits are closely related to GERD symptoms..$^{6-8}$

The results of this study were meaningful in that food information that would directly help gastroesophageal reflux patients were provided. However, 3 months' duration of GERD symptoms, the recall bias, small sample size, heterogeneous participants, possibility of aggravating factor rather than a causative factor, and residual confoundings (eating habits, lifestyle, and genetic risk factors) were major limitations of this paper. Further research considering such problems will be necessary in the future.

\section{Financial support: None.}

\section{Conflicts of interest: None.}

\section{References}

1. Chey WD. The role of food in the functional gastrointestinal disorders: introduction to a manuscript series. Am J Gastroenterol 2013;108:694697.

2. Gibson PR, Shepherd SJ. Food choice as a key management strategy for functional gastrointestinal symptoms. Am J Gastroenterol 2012;107:657-

Received: June 5, 2017 Revised: June 7, 2017 Accepted: June 8, 2017

(a) This is an Open Access article distributed under the terms of the Creative Commons Attribution Non-Commercial License (http://creativecommons. org/licenses/by-nc/4.0) which permits unrestricted non-commercial use, distribution, and reproduction in any medium, provided the original work is properly cited.

*Correspondence: Jung Ho Park, MD

Department of Medicine, Kangbuk Samsung Hospital, Sungkyunkwan University College of Medicine, 29 Saemunan-ro, Jongno-

Ku, Seoul 03181, Korea

Tel: +82-2-2001-2059, Fax:+82-2-2001-2485, E-mail: pjho3@hotmail.com 
666.

3. Dore MP, Maragkoudakis E, Fraley K, et al. Diet, lifestyle and gender in gastro-esophageal reflux disease. Dig Dis Sci 2008;53:2027-2032.

4. Monnikes H, Tebbe JJ, Hildebrandt M, et al. Role of stress in functional gastrointestinal disorders. Dig Dis 2001;19:201-211.

5. Choe JW, Joo MK, Kim HJ, et al. Foods inducing typical gastroesophageal reflux disease symptoms in Korea. J Neurogastroenterol Motil 2017;23:363-369.
6. Holloway RH, Lyrenas E, Ireland A, Dent J. Effect of intraduodenal fat on lower oesophageal sphincter function and gastro-oesophageal reflux. Gut 1997;40:449-453.

7. Milke P, Diaz A, Valdovinos MA, Moran S. Gastroesophageal reflux in healthy subjects induced by two different species of chilli (Capsicum annum). Dig Dis 2006;24:184-188

8. Orlando RC. Reflux esophagitis: overview. Scand J Gastroenterol 2009;30:36-37. 